\title{
A Morphometric Study of Lumbar Spine Pedicles in Nepalese Popula- tion
}

\author{
Rudra Prasad Marasini ${ }^{1}$, Pratiksha Gautam ${ }^{1}$, Binod Sherchan ${ }^{2}$, Ganesh Gurung ${ }^{2}$, Bachchu Ram KC \\ ${ }^{1}$ Department of Orthopedics and Trauma, Bharatpur Hospital, Chitwan, Nepal \\ ${ }^{2}$ Department of Orthopedics and Trauma, National Academy of Medical Sciences, Bir Hospital, Kathmandu, \\ Nepal \\ ${ }^{3}$ Department of Orthopedics and Trauma, Shree Birendra Hospital, Chhauni, Kathmandu, Nepal
}

\section{Correspondence \\ Rudra Prasad Marasini}

Department of Orthopedics and Trauma,

Bharatpur Hospital, Chitwan, Nepal

E-mail: drmarasinirp@gmail.com

DOI: http://dx.doi.org/10.3126/

jcmsn.v10i4.12972

\begin{abstract}
Background and Objective: In this observational study, morphometric data were obtained and analyzed by taking plain $\mathrm{x}$-rays in various age groups to establish the morphometric values in Nepalese population. Methods: All the pedicle dimensions were measured by taking plain $\mathrm{x}-$ ray AP (Antero-posterior) and Lateral view of the lumbar spine in 246 Nepalese of different age groups. Pedicle diameters (Vertical and Horizontal) and interpedicular distance were measured in AP radiographs and sagittal angle was measured in the lateral radiographs. Differences between mean dimensions of pedicles of male and female of various age groups were tested by using ANOVA, independent t-test was used to test the individual mean dimensions. Results: Mean values of the pedicle dimensions were found as: Horizontal diameter $(\mathrm{L} 1=7.17 \mathrm{~mm}$, $\mathrm{L} 2=7.26 \mathrm{~mm}, \mathrm{~L} 3=9.50 \mathrm{~mm}, \mathrm{~L} 4=10.57 \mathrm{~mm}$ and $\mathrm{L} 5=11.3 \mathrm{~mm})$, Vertical diameter $(\mathrm{L} 1=15.00 \mathrm{~mm}, \mathrm{~L} 2=15.28 \mathrm{~mm}, \mathrm{~L} 3=15.21 \mathrm{~mm}, \mathrm{~L} 4=13.44 \mathrm{~mm}$ and $\mathrm{L} 5=12.59 \mathrm{~mm})$, Interpedicular distance $(\mathrm{L} 1=25.54 \mathrm{~mm}, \mathrm{~L} 2$ $=27.03 \mathrm{~mm}, \mathrm{~L} 3=27.70 \mathrm{~mm}, \mathrm{~L} 4=28.62 \mathrm{~mm}$ and L5 $=31.29 \mathrm{~mm})$ and the sagittal angle $(\mathrm{L} 1=17.83$ degree, $\mathrm{L} 2=15.7$ degree, $\mathrm{L} 3=15.91$ degree, L4=13.94degree, and L5=12.97degree) respectively. Conclusions: Values of pedicle dimensions found in Nepalese population by this study can be guidelines for the transpedicular procedure and for further research activities.
\end{abstract}

Keywords: Interpedicular distance; Lumbar vertebrae; Pedicle; sagittal angle.

Citation: Marasini RP, Gautam P, Sherchan B, et al. A morphometric study of lumbar spine pedicles in Nepalese population. JCMS Nepal 2014;10(4):12-7.

\section{INTRODUCTION}

Transpedicular approaches are being widely used in many surgeries such as bone biopsy, bone grafting, pedicle screw fixation, vertebroplasty and kyphoplasty. ${ }^{1}$ The pedicle has been described as "the force nucleus" of the spine, where the posterior elements converge before their communication with the more anterior vertebral body. ${ }^{2}$ Several morphometric studies of vertebral pedicles were performed by using plain X-ray, CT scan and anatomic specimens, ${ }^{3-9}$ and the significant difference between the pedicle dimensions of white and Asian populations (Indian, Chinese, Korean and Malaysian) as well as variations in different age groups, races, and ethnic groups have been documented. ${ }^{3,5-}$ 7,10-16. Those studies established that measurements obtained from the plain x-ray films correlated well with values measured from $\mathrm{CT}$ scan and cadavers, ${ }^{4,7-9,17}$ since plain $\mathrm{x}$-ray is the cheap and easily available method and whole lumbar spine (L1-L5) can be included in the single x-ray film, so that we have preferred this method for the measurement of 
pedicle dimensions.

\section{MATERIALS AND METHODS}

This observational study was performed in the National Academy of Medical Sciences (NAMS), Shree Birendra Hospital Chhauni, Kathmandu and Bharatpur Hospital, Chitwan, Nepal within the period of 4 years (April 2010 to March 2014). Those individuals who visited in the OPD with minor complains of backache $($ Total $=246$, male 127 $=51.6 \%$ and female $119=48.4 \%$ ) of various age groups ( $>10 \mathrm{yrs})$ were included. Peoples having history of spinal surgery, deformities and pre-existing spinal pathology were excluded. Plain x-ray lumbar spine AP (Antero-posterior) and Lateral view, which includes L1- L5, were obtained by maintaining the same FFD (Focus film distance) and SFD (Subject film distance). These distances (FFD and SFD) were maintained by taking the metal piece as a reference by maintaining the magnification factor as one in all the three institutions. Those $\mathrm{x}$ - ray films, which were reported by consultant radiologist as normal, were only kept for examination.

Measurements were performed by standard Scale of $1 \mathrm{~mm}$ and Goniometer of one degree calibration. In AP radiographs pencil marks were placed on the limits of the pedicle and diameter was measured in two perpendicular planes (Vertical $=\mathrm{V}$ and Horizontal $=\mathrm{H}$ ). Vertical diameter was taken as a maximum diameter in the sagittal plane and Horizontal diameter was taken as a maximum diameter in a plane right angle to the vertical. Interpedicular distance (IPD) was measured by horizontal line joining the innermost cortical border of the two adjacent pedicles of the vertebrae in the AP radiographs. Sagittal angle (SA) was measured by drawing one line along the axis of the pedicle and another line along the superior border of the vertebral body in the lateral radiographs (Figure 1). Illustrations of horizontal diameter, vertical diameter and sagittal angle to be measured are also mentioned here (Figure 2). ${ }^{18}$

Data was analyzed by using statistical program spss16. Mean dimensions, Standard error of means (SEM), Standards deviations (SD) and p-values of all the vertebral level were calculated separately.

Differences between mean dimensions of pedicles of male and female of various age groups were tested by means of analysis of variance (ANOVA). In combination with ANOVA, independent t-test was used to test the individual mean dimensions and $95 \%$ confidence limits were considered for both sexes and age groups at all levels.

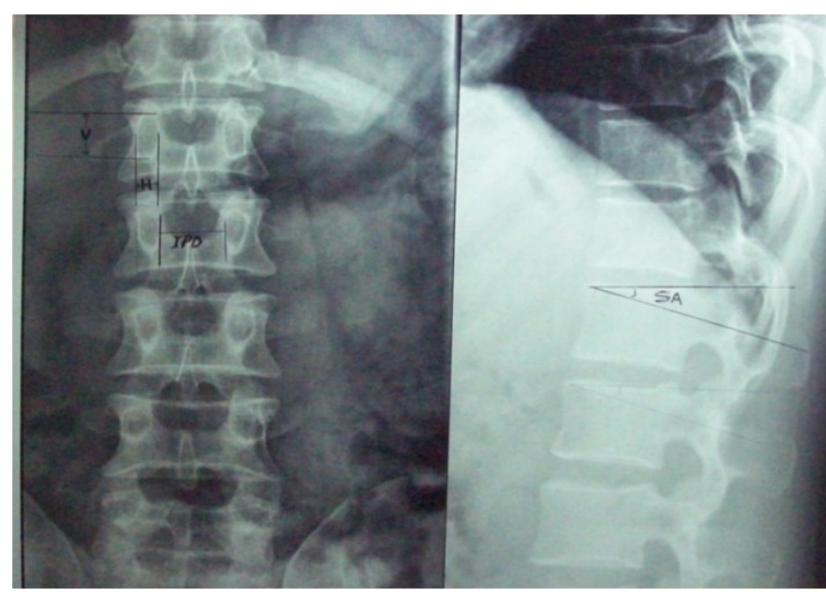

Figure 1: X-ray showing the methods of measurement of pedicle dimensions

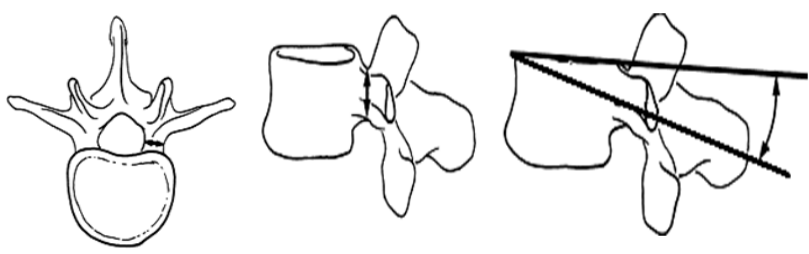

Figure 2: Shows illustrations of horizontal diameter, vertical diameter and sagittal angle, which has been measured in $\mathrm{x}$-ray film

\section{RESULTS}

In this study mean horizontal diameter ranges from $7.17 \mathrm{~mm}$ to $11.30 \mathrm{~mm}$. Mean horizontal diameter increases from $\mathrm{L} 1$ to $\mathrm{L} 5$ level $(\mathrm{L} 1=7.17, \mathrm{~L} 2=7.26$, $\mathrm{L} 3=9.5, \mathrm{~L} 4=10.57$ and $\mathrm{L} 5=11.30 \mathrm{~mm}$ ). Mean vertical diameter ranges from $12.59 \mathrm{~mm}$ to $15.28 \mathrm{~mm}$, maximum vertical diameter were measured at L2 $(15.28 \mathrm{~mm})$ and minimum at L5 $(12.59 \mathrm{~mm})$ but the diameters were not decreases linearly from L1 -L5 (L1 $=15.00, \mathrm{~L} 2=15.28, \mathrm{~L} 3=15.21, \mathrm{~L} 4=13.44$ and $\mathrm{L} 5=12.59 \mathrm{~mm})$. Horizontal and vertical diameters of the right and left side were measured and 
compared separately at all levels. Dimensions of the right and left sides were found different at all levels but the difference was not found significant statistically. We found that the interpedicular distance (IPD) increases linearly from L1 to L5 and mean values were found as $25.54 \mathrm{~mm}$ at L1, $27.03 \mathrm{~mm}$ at $\mathrm{L} 2,27.70 \mathrm{~mm}$ at $\mathrm{L} 3,28.62 \mathrm{~mm}$ at $\mathrm{L} 4$, and 31.29 $\mathrm{mm}$ at L5. Sagittal angle of the Pedicles were directed cephaled in some vertebrae and caudal in others. Mean values of the sagittal angle were calculated separately for cephalic and caudal directed pedicles and found as follow: L1 $=17.83$ degrees, $\mathrm{L} 2=15.7$ degrees, $\mathrm{L} 3=15.91$ degrees, $\mathrm{L} 4=13.94$ degrees, L5=12.97 degrees (Table 1).

Table 1: Mean values of pedicle dimensions

\begin{tabular}{|l|c|c|c|c|c|}
\hline Measurement & L1 & L2 & L3 & L4 & L5 \\
\hline $\begin{array}{l}\text { Mean HD } \\
(\mathrm{mm})\end{array}$ & 7.17 & 7.62 & 9.50 & 10.57 & 11.30 \\
\hline $\begin{array}{l}\text { Mean VD } \\
(\mathrm{mm})\end{array}$ & 15.00 & 15.28 & 15.21 & 13.44 & 12.59 \\
\hline $\begin{array}{l}\text { Mean IPD } \\
(\mathrm{mm})\end{array}$ & 25.54 & 27.03 & 27.70 & 28.62 & 31.39 \\
\hline $\begin{array}{l}\text { Mean SA } \\
\text { (degree) }\end{array}$ & 17.83 & 15.70 & 15.91 & 13.94 & 12.97 \\
\hline
\end{tabular}

Out of 246 individuals most of the pedicles were found to directed cephalic (L1=198, L2 $=203, \mathrm{~L} 3=$ 203, L4= 173) except at L5 levels, where most of the pedicles (171) were found directed caudally. We also analyzed the sex related variations and significant difference was found between male and female except at few levels. Variation in the pedicle dimensions were also found in different age groups but the difference was not compared separately in each group.

\section{DISCUSSION}

Several studies regarding morphometric measurement of vertebral pedicles were performed by using $\mathrm{X}$-ray, CT scan and anatomic specimens and a significant variation of pedicle dimensions were found in different age groups, sex, races, and ethnic groups. $1,4,5,8,13-16,19$
Those studies had established that measurements obtained from the plain $\mathrm{x}$-ray films correlated well with values measured from CT scan and directly measured from cadavers. ${ }^{1,4,7,13,15,18,20,21}$ AmonooKuofi HS et $\mathrm{al}^{4}$ performed the similar study in 540 persons $(270=$ male and 270 female $)$ with age ranging from 10- 65 years by using plain X-ray AP view only to measure horizontal and vertical diameter of lumbar spine pedicles and found the significant variations between the different age groups and sex. Zindric et $\mathrm{al}^{7}$ and Panjabi MM et al ${ }^{19}$ also used plain $\mathrm{x}$-ray to measure the pedicle dimensions and compared with morphometric measurement from cadavers and found that plain $\mathrm{x}$-ray values are comparable to the directly measured values. We found that mean horizontal diameter ranged from $7.17 \mathrm{~mm}$ to $11.30 \mathrm{~mm}$. Horizontal diameter increases from L1 to $\mathrm{L} 5$ level $(\mathrm{L} 1=7.17 \mathrm{~mm}, \mathrm{~L} 2=7.26 \mathrm{~mm}, \mathrm{~L} 3=9.50$ $\mathrm{mm}, \mathrm{L} 4=10.57 \mathrm{~mm}$ and $\mathrm{L} 5=11.30 \mathrm{~mm}$ ). Mean vertical diameter ranges from $12.59 \mathrm{~mm}$ to $15.28 \mathrm{~mm}$, maximum vertical diameter were measured at $\mathrm{L} 2$ $(15.28 \mathrm{~mm})$ and minimum at L5 $(12.59 \mathrm{~mm})$ but the diameters were not decreases linearly from L1 to $\mathrm{L} 5(\mathrm{~L} 1=15 \mathrm{~mm}, \mathrm{~L} 2=15.28 \mathrm{~mm}, \mathrm{~L} 3=15.21 \mathrm{~mm}$, $\mathrm{L} 4=13.44 \mathrm{~mm}$ and $\mathrm{L} 5=12.59 \mathrm{~mm}$ ). Horizontal and vertical diameters of the right and left side were measured separately and compared at all levels. Dimensions of the right and left sides were found different at all levels but the difference was not significant statistically (P-value at $95 \%$ of confidence interval was $>0.05$ at all levels).

Our mean values were also compared with the previous Morph metric studies. In the study done by Zindric et $\mathrm{al}^{7}{ }^{7}$ mean horizontal diameter ranged from $8.7 \mathrm{~mm}$ at L1 level to $18 \mathrm{~mm}$ at L5 level and mean vertical diameter ranged from $15.4 \mathrm{~mm}$ at $\mathrm{L} 1$ level to $12.59 \mathrm{~mm}$ at L5 level. Outer diameters of the most commonly used pedicle screws range from $5 \mathrm{~mm}$ to $7 \mathrm{~mm}$ so that the screw pitch, tooth profile, outer diameter, and depth of penetration should be considered while putting the pedicle screws. ${ }^{15}$ In this Morphometric study, variations of the pedicle dimensions were observed between different sex and age groups. Pedicle diameters were also 
compared between male and female sex at all levels (by using independent sample t-test at $95 \%$ confidence interval) and with the previous morphometric studies done by Olsewiski JM et $\mathrm{al}^{15}$ and Mitra SR et $\mathrm{al},{ }^{18}$ we found that mean horizontal diameter in male varies from $7.73 \mathrm{~mm}$ (L1) to $10.89 \mathrm{~mm}$ (L5) and in female from $6.57 \mathrm{~mm}$ (L1) to $11.94 \mathrm{~mm}$ (L5), mean vertical diameter in male vary from $16.23 \mathrm{~mm}$ (L2) to $12.97 \mathrm{~mm}$ (L5). Similarly Mitra SR et al ${ }^{5}$ performed Morphometric study in the Indian population and found that mean horizontal diameter in male ranged from $7.05 \mathrm{~mm}$ (L1) to $11.94 \mathrm{~mm}$ (L5) and in female from $5.95 \mathrm{~mm}$ (L1) to $10.61 \mathrm{~mm}$ (L5). Olsewiski JM et al ${ }^{18}$ (1990) found that mean horizontal diameter in male ranged from $9.00 \mathrm{~mm}(\mathrm{~L} 1)$ to $16.7 \mathrm{~mm}(\mathrm{~L} 5)$ and in female from $6.30 \mathrm{~mm}(\mathrm{~L} 1)$ to $13.5 \mathrm{~mm}$ (L5), mean vertical diameter in male ranged from $16.8 \mathrm{~mm}$ (L2) to $14.2 \mathrm{~mm}$ (L4) and in female $15.4 \mathrm{~mm}$ (L1) to $13.2 \mathrm{~mm}$ (L5). Mean values of pedicle diameter in our study were found smaller than all the above studies at most of the vertebral levels but the values obtained by Mitra SR et $\mathrm{al}^{15}$ were very similar to our study; it may be due to various socioeconomic, cultural and structural similarities between Nepalese and Indian population. All of these authors found that pedicle diameters differ significantly between male and female at all the levels as in our study (Figure 3, 4).

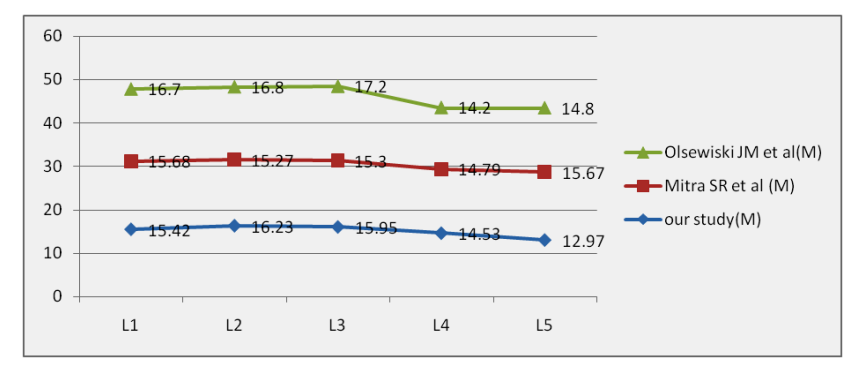

Figure 3: Graph showing the comparison of horizontal diameter (millimeter)

We found that the interpedicular distance increases linearly from L1 to L5. Mean interpedicular distance were found as $\mathrm{L} 1=25.54 \mathrm{~mm}, \mathrm{~L} 2=27.03$ $\mathrm{mm}, \mathrm{L} 3=27.70 \mathrm{~mm}, \mathrm{~L} 4=28.62 \mathrm{~mm}$ and at L5 $=31.29 \mathrm{~mm}$. These values also differed significantly between male and female and with different age groups. Similar pattern was observed by Mitra SR et $\mathrm{al}^{15}$ but their values were larger than our values at all the levels. They found that the interpedicular distance in male at $\mathrm{L} 1=32.4 \mathrm{~mm}, \mathrm{~L} 2=32.8 \mathrm{~mm}$, $\mathrm{L} 3=33.4 \mathrm{~mm}, \mathrm{~L} 4=34 \mathrm{~mm}, \mathrm{~L} 5=34.1 \mathrm{~mm}$ and in female $\mathrm{L} 1=32.5 \mathrm{~mm}, \mathrm{~L} 2=34.4 \mathrm{~mm}, \mathrm{~L} 3=34 \mathrm{~mm}$ and $\mathrm{L} 4$ $=35 \mathrm{~mm}$ (Figure 5).

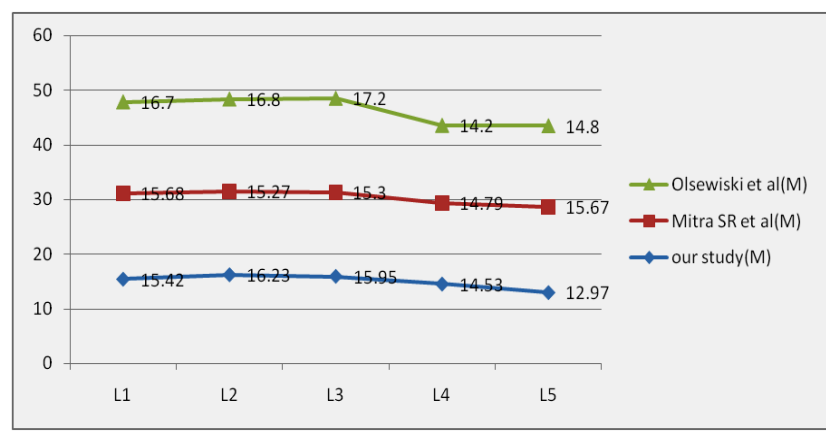

Figure 4: Graph showing the comparison of vertical diameter (millimeter)

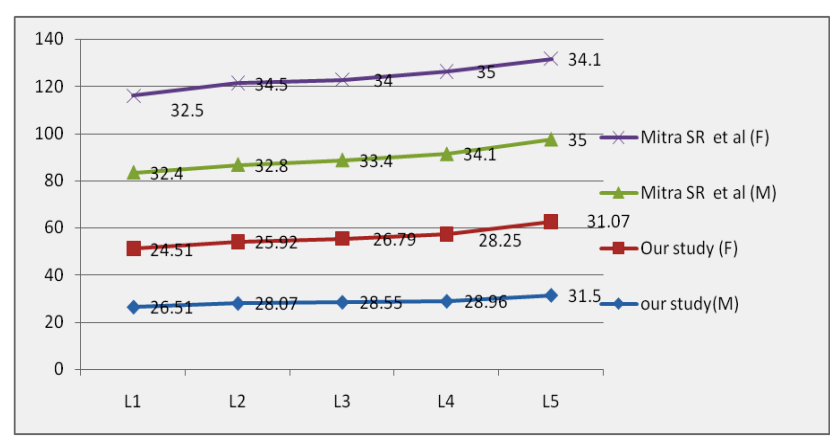

Figure 5: Graph showing the comparison of interpedicular distance (millimeter)

In this study sagittal angle of the vertebrae were also measured in plain $\mathrm{x}$ - ray lateral views. Pedicles were found directed cephalic in some vertebrae and caudal in others. Out of 246 vertebrae analyzed; most of the pedicles were directed cephalic $(\mathrm{L} 1=198, \mathrm{~L} 2=203, \mathrm{~L} 3=203, \mathrm{~L} 4=173)$ except at L5 levels where maximum pedicles (171) were found of directed caudally. Similar pattern was observed by Marchesi D et al, ${ }^{9}$ they found that in the sagittal plane, the pedicles were angled cephaled from T6 to L3 and slightly caudally at L5. In our study, mean values of the sagittal angle were calculated separately for cephalic and caudally directed vertebrae and found as follows: L1=17.83 degree, L2 $=15.7$ degree, L3= 15.91 degree, L4=13.94 degree and 
L5 $=12.97$ degrees. Similar studies were performed by Olsewiski JM et $\mathrm{al}^{18}$ and Mitra SR et al, ${ }^{15}$ but they considered values of cephaled directed pedicles as positive and caudally directed pedicles as negative and means were calculated by adding all the values together. Olsewiski JM et al ${ }^{18}$ found that the mean sagittal angle of $\mathrm{L} 1=5$ degree, $\mathrm{L} 2=6$ degree, L3 $=6$ degree, L4 $=7$ degree and L5 $=5$ degree, similarly Mitra SR et $\mathrm{al}^{15}$ found mean values as $\mathrm{L} 1=8.4$ degree, $\mathrm{L} 2=9.3$ degree, $\mathrm{L} 3=10.4$ degree and $\mathrm{L} 5=6.7$ degree. Values obtained by both of these authors were smaller than our values, it might be due to the different techniques of calculation but in all the above studies it had been observed that values of sagittal angle were decreases as we go downwards from L1 to L5 vertebral levels. Our values are very similar to the values obtained by Fang $\mathrm{D}$ et $\mathrm{al},{ }^{6}$ in which they mentioned that: Asian pedicles had a larger pedicle inclination angle from $\mathrm{L} 1$ to $\mathrm{L} 4(\mathrm{~L} 1=16$ degrees, $\mathrm{L} 2=16$ degrees, $\mathrm{L} 3=19$ degrees, $L 4=23$ degrees and L5 $=29$ degrees) and there was a significant differences between the lumbar pedicles of Asians and whites.

We analyzed sex related variations of pedicle dimensions by comparing the values between male and female as grouping variables and all the other parameters separately as test variables by using Independent Samples- $T$ Test at 95\% confidence interval. Significant difference in the horizontal diameter between male and female pedicle were found at all levels ( $\mathrm{p}$-value $=<0.05$ ) except at L5 levels $(p$-value $=0.062)$. Similarly the difference in the vertical diameter between male and female was also found statistically significant at all levels ( $p$ value $=<0.05)$ except at $\mathrm{L} 1$ ( $\mathrm{p}$-value $=0.136)$ and L5 $(\mathrm{p}-\mathrm{value}=0.062)$. The difference in the interpedicular distance was also found significant at all the level except at L1 $(\mathrm{p}=0.22)$ and L3 $(\mathrm{p}=0.26)$. As in our study sex and age related variations was observed by several authors. ${ }^{1,4,13,15,20,22}$

Age groups related variation between different age groups was analyzed by using One-way ANOVA at $95 \%$ confidence interval but the variations were not compared between each age group separately. Significant age groups related variations were observed in all the pedicle dimensions at all vertebral level $(\mathrm{p}=<0.005)$ except the sagittal diameter at L5 level, where the different was not significant (pvalue $=0.108$ ). In this study the findings suggested that there was continuous variations in the pedicle dimensions and the changes were characterized by increase of diameters in some age groups and decrease in others, but there was an overall increase in the dimensions as the age groups were followed from the youngest to the oldest.

AmonooKuofi et $\mathrm{al}^{4}$ also found that there was a significant age related variations of pedicle dimensions at all segmental levels. Mitra SR et a ${ }^{15}$ performed the Morphometric study of the pedicles in the Indian population and found the significant difference with white population but they didn't analyze the values between different ethnic groups within the Indian population. Liau KM et $\mathrm{al}^{16}$ did the similar study in the Malaysian Malay population and found that female patients had the significantly smaller dimensions in most of the parameters measured as compared to male and the pedicles dimensions of the Malay populations differ significantly with white.

\section{CONCLUSION}

By this limited study, we can recommend that the pedicle dimensions of lumbar spine in Nepalese population, could be a guidelines for all the transpedicular procedures and research activities though we need to have further studies based on direct morphometric measurement and CT- Scan including all the vertebral levels (cervical, thoracic and lumbar). Pedicle dimensions of Nepalese are very similar to that of Indian population but differ significantly with white populations and most of these values were found smaller than those of white

populations. Pedicle screw sizes which are being used now a day may not be appropriate for all the vertebral levels in Nepalese population so that selecting an appropriate size pedicle screw and the 
direction of insertion are very crucial while performing the transpedicular procedures.

\section{REFERENCES}

1. Lien SB, Liou NH, Wu SS. Analysis of anatomic morphometry of the pedicles and the safe zone for throughpedicle procedures in the thoracic and lumbar spine. Eur Spine J2007;16(8):1215-22. DOI: 10.1007/s00586-0060245-2. PMid:17180401.

2. Vaccaro A, Garfin S. Pedicle-Screw Fixation in the Lumbar Spine. J Am Acad Orthop Surg1995;3(5):263-74.

3. Acharya S, Dorje T, Srivastava A. Lower dorsal and lumbar pedicle morphometry in Indian population: a study of four hundred fifty vertebrae. Spine (Phila $\mathrm{Pa}$ 1976) $2010 ; 35$ :E 378 -E384. DOI: $10.1097 /$ BRS.0b013e3181cb7f2. PMid:20431473.

4. Amonoo-Kuofi HS. Age-related variations in the horizontal and vertical diameters of the pedicles of the lumbar spine. J Anat 1995;186(2):321-8.

5. Datir SP, Mitra SR. Morphometric study of the thoracic vertebral pedicle in an Indian population. Spine (Phila $\mathrm{Pa}$ 1976) 2004;29(11):1174-81. DOI: 10.1097/00007632200406010-00004.

6. Fang D, Cheung KM, Ruan D, Chan FL. Computed tomographic osteometry of the Asian lumbar spine. J Spinal Disord 1994;7:307-16. DOI: 10.1097/00002517199408000-0000. PMid:7949698.

7. Zindrick MR, Wiltse LL, Doornik A, et al. Analysis of the morphometric characteristics of the thoracic and lumbar pedicles. Spine (Phila Pa 1976)1987;12:160-6. DOI: 10.1097/00007632-198703000-00012.

8. Robertson PA, Stewart NR. The radiologic anatomy of the lumbar and lumbosacral pedicles. Spine (Phila Pa 1976) 2000;25(6):709-15. DOI: 10.1097/00007632-20000315000010 .

9. Marchesi D, Schneider E, Glauser P, Aebi M. Morphometric analysis of the thoracolumbar and lumbar pedicles, anatomo-radiologic study. Surg Radiol Anat 1988;10:317-22.DOI: 10.1007/BF02116454.

10. Zhuang Z, Xie Z, Ding S, et al. Evaluation of thoracic pedicle morphometry in a Chinese population using 3D reformatted CT. Clin Anat 2012;25:461-7. DOI: 10.1002/ ca.21265. PMid:22488996.

11. Hou S, Hu R, Shi Y. Pedicle morphology of the lower thoracic and lumbar spine in a Chinese population. Spine (Phila Pa 1976) 1993;18:1850-5.DOI: 10.1097/00007632199310000-00021.

12. Kim NH, Lee HM, Chung IH, Kim HJ, Kim SJ. Morphometric study of the pedicles of thoracic and lumbar vertebrae in Koreans. Spine (Phila Pa 1976) 1994;19:1390 -4. DOI: 10.1097/00007632-199406000-00014.

13. Chadha M, Balain B, Maini L, Dhaon BK. Pedicle morphology of the lower thoracic, lumbar, and S1 vertebrae: an Indian perspective. Spine (Phila Pa 1976) 2003;28(8):
744-9.

14. Christodoulou AG, Apostolou T, Ploumis A, Terzidis I, Hantzokos I, Pournaras J. Pedicle dimensions of the thoracic and lumbar vertebrae in the Greek population. Clin Anat2005;18(6):404-8. DOI: 10.1002/ca.20155.

15. Mitra SR, Datir SP, Jadhav SO. Morphometric study of the lumbar pedicle in the Indian population as related to pedicular screw fixation. Spine (Phila Pa 1976) 2002;27 (5):453-9. DOI: 10.1097/00007632-200203010-00004.

16. Liau KM, Yusof MI, Abdullah MS, Abdullah S, Yusof AH. Computed tomographic morphometry of thoracic pedicles: safety margin of transpedicular screw fixation in Malaysian Malay population. Spine (Phila $\mathrm{Pa}$ 1976) $2006 ; 31\left(\begin{array}{ll}1 & 6\end{array}\right): 545-50$. D O I : 10.1097/01.brs.0000225978.97652.e0. PMid:16845341.

17. Hailong Y, Wei L, Zhensheng M, Hongxun S. Computer analysis of the safety of using three different pedicular screw insertion points in the lumbar spine in the Chinese population. Eur Spine J 2007;16:619-23. DOI: 10.1007/ s00586-006-0243-4. PMid:17039382.

18. Olsewski JM, Simmons EH, Kallen FC, Mendel FC, Severin CM, Berens DL. Morphometry of the lumbar spine: anatomical perspectives related to transpedicular fixation. J Bone Joint Surg Am 1990;72:541-49. PMid:2139030

19. Panjabi MM, O’Holleran JD, Crisco JJ, Kothe R. Complexity of the thoracic spine pedicle anatomy. Eur Spine $\mathrm{J}$ 6(1):19-24. DOI: $10.1007 / \mathrm{BF} 01676570$. PMid:9093823.

20. Srikumaran U, Woodard EJ, Leet AI, Rigamonti D, Sponseller PD, Ain MC. Pedicle and spinal canal parameters of the lower thoracic and lumbar vertebrae in the achondroplast population. Spine (Phila Pa 1976) 2007;32(22):242331. DOI: $10.1097 /$ BRS.0b013e3181574286. PMid:18090080.

21. Ebraheim NA, Rollins JR, Xu R, Yeasting RA. Projection of the lumbar pedicle and its morphometric analysis. Spine (Phila Pa 1976) 1996;21:1296-1300. DOI: 10.1097/00007632-199606010-00003.

22. Whang PG, Vaccaro AR. Spinal Pedicle Fixation Revisited: The Role of X-rays and Other Surgical Factors. Spine (Phila Pa 1976) 2006;31(6):717-21. DOI: 10.1097/01.brs.0000207177.25863.9a. 